\title{
Update Equipment Critically Rating Dan Analisa Kestabilan Maintenance Equipment Kategori A Dengan Nilai Mean Time Between Failures Di Pabrik PA1 B0102 PT Petrokimia Gresik
}

\author{
Arnes Setya Prayogo ${ }^{1}$, R. Fairuz Zamani ${ }^{2}$ Novi Sukma Drastiawati ${ }^{3}$ \\ 1,3 Arnes Setya Prayogo, Novi Sukma Drastiawati (Teknik Mesin/D-3 Produksi, Universitas Negeri Surabaya) \\ 'arnesprayogo16050423004@mhs.unesa.ac.id \\ ${ }^{3}$ novidrastiawati@unesa.ac.id \\ ${ }^{2}$ Petrokimia Gresik, Indonesia \\ ${ }^{2}$ fairuz.zamani@petrokimia-gresik.com
}

\begin{abstract}
Abstrak- Hasil update ECR (Equipment Critically Rating) pada pabrik PA1 functional location $\mathrm{B0102}$ ditemukan beberapa equipment yang sudah tidak digunakan, beberapa equipment turun tingkat krtitisnya dibandingkan dengan sebelumnya, hal ini dikarenakan perbedaan metode dalam penggolongan ECR. Metode yang saya gunakan merupakan metode baru yang diterapkan tahun 2018 oleh Departemen Pemeliharaan III PT Petrokimia Gresik.Data Trend MTBF dari equipment kategori A menunjukan banyaknya peralatan yang belum handal, kegiatan maintenance di Departemen Pemeliharaan III masih kurang efektif sehingga rata-rata waktu equipment bekerja dalam satu tahun tidak stabil.
\end{abstract}

Kata Kunci- ECR, MTBF, equipment

Abstract - The results of the ECR update (Equipment Critically Rating) at the PA1 functional location B0102 factory found some equipment that has not been used, some equipment dropped the critical level compared to before, this was due to different methods in ECR classification. The method that $I$ use is a new method that was implemented in 2018 by the Maintenance Department III of PT Petrokimia Gresik. Data on MTBF Trend from equipment category $A$ shows the number of equipment that has not been reliable, maintenance activities at Department of Maintenance III are still ineffective so that the average equipment time works in one year is not stable.

Key Words - ECR, MTBF, equipment.

\section{Pendahuluan}

\section{A. Latar Belakang}

Sejalan dengan tuntutan industri terkait dengan kemampuan SDM (Sumber Daya Manusia), maka perguruan tinggi semakin berusaha meningkatkan mutu dari mahasiswanya agar bisa berkembang sesuai dengan perkembangan teknologi baru di industri yang ada di Indonesia maupun dunia. Pada awalnya teknologi berkembang secara lambat, seiring dengan kemajuan tingkat kebudayaan dan peradaban manusia, teknologi berkembang dengan cepat. Semakin maju kebudayaannya, semakin berkembang teknologinya karena teknologi merupakan perkembangan dari kebudayaan yang maju dan pesat (Adib, 2011, p.254).

Universitas Negeri Surabaya merupakan salah satu universitas negeri di Indonesia yang selalu berupaya meningkatkan mutu SDM dan IPTEK guna menunjang kemajuan negara Indonesia. Sehubungan dengan cepatnya perkembangan teknologi yang ada di industri, maka wawasan dari mahasiswa tentang teknologi dirasa sangat kurang, sehingga kerjasama dengan perusahaan sangat diperlukan, hal ini dapat dilakukan dengan berbagai cara seperti Studi Ekskursi, Kerja Praktik, Magang, dan Joint Research.

Kerjasama yang baik antara perusahaan dengan perguruan tinggi ini dapat menghasilkan lulusan yang berkualitas guna membantu perkembangan bangsa. Saya sebagai mahasiswa diharapkan mampu mengenal serta memahami metode dan teknologi baru yang digunakan perusahaan. Praktik Industri merupakan salah satu kurikulum wajib yang harus ditempuh oleh mahasiswa Jurusan Teknik Mesin Universitas Negeri Surabaya (UNESA). Pemahaman tentang permasalahan di dunia industri khususnya di bidang produksi serta maintenance untuk mahasiswa Jurusan Teknik Mesin UNESA sangat diperlukan guna menunjang pengetahuan secara teoritis yang didapat dari materi saat perkuliahan, sehingga mahasiswa menjadi salah satu sumber daya manusia yang berkualitas dan siap menghadapi dunia kerja.

PT Petrokimia Gresik merupakan produsen pupuk terlengkap di Indonesia yang memproduksi berbagai macam pupuk dan bahan kimia untuk solusi argoindustri. Perusahaan berlogo Kebomas dan berlokasi di Kabupaten Gresik, Jawa Timur, Indonesia ini adalah anak usaha PT Pupuk Indonesia (PERSERO). PT Petrokimia Gresik Berkomitmen untuk terus tumbuh dan berkembang bersama masyarakat demi mendukung terwujudnya ketahanan pangan nasional dan kemajuan dunia pertanian (PT Petrokimia Gresik). 
Kegiatan produksi merupakan salah satu faktor penting dalam setiap perusahaan, apabila proses produksi dalam suatu pabrik terhenti dalam waktu yang lama maka perusahaan akan mengalami production lost atau kerugian karena tidak dapat menghasilkan produk. Kegiatan produksi di PT Petrokimia Gresik dilakukan selama 24 jam tanpa henti. Penggunaan peralatan secara terus menerus pasti akan menyebabkan kerusakan, hal tersebut jelas akan berdampak pada kelancaran proses produksi di perusahaan. Demi menjaga kualitas peralatan produksi tetap baik maka dilakukan pemeliharaan dan perawatan yang rutin dan terencana agar kegiatan produksi tidak terganggu. Tujuan utama pemeliharaan (maintenance) adalah menjaga nilai aset peralatan produksi dengan cara mengembalikan performa peralatan sesuai desain (PT Petrokimia Gresik). Kegiatan pemeliharaan (maintenance) meliputi perencanaan, perbaikan, pengawasan, penggantian suku cadang, dan improvement kehandalan. Selain itu, peranan perawatan peralatan produksi sangat penting guna menjaga kegiatan produksi berjalan dengan baik dan lancar sehingga terhindar dari kerugian akibat downtime peralatan yang berdampak pada production lost.

Pada kesempatan ini saya akan menguraikan bagaimana proses analisa kestabilan nilai MTBF (Mean Time Between Failures) suatu equipment selama beberapa tahun dengan memanfaatkan nilai ECR kategori A untuk menilai kegiatan maintenance yang sudah diterapkan benar-benar efektif. Tidak ada metode yang baku dalam penentuan nilai ECR (Equipment Critically Rating), penyusunan bergantung pada karakteristik pabrik atau best practices di lapangan, adapun penyusunan nilai ECR yang saya lakukan adalah dengan menganalisa dampak dan peluang dari kegagalan peralatan.

Penentuan nilai ECR sangat penting dilakukan di awal perencanaan maintenance karena dengan menggolongkan tingkat kritis equipment dapat mengetahui seberapa vital alat tersebut, karena bisa jadi alat yang hanya memerlukan service atau maintenance dalam 1 atau 2 tahun sekali merupakan alat yang memiliki dampak berbahaya bagi operator atau lingkungan jika terjadi suatu kegagalan saat beroperasi, dengan menggunakan nilai ECR ini dapat menjadi rujukan prioritaskan equipment yang akan dilakukan proses maintenance sesuai dengan ketentuan.

Dengan adanya nilai ECR dan MTBF ini dapat diketahui equipment mana yang benar-benar kritis dan bisa digunakan untuk rujukan pemantauan efektivitas dari pola maintenance suatu equipment sehingga pola preventive maintenance yang kurang efektif tersebut dapat diperbarui lagi agar hasilnya lebih stabil supaya peralatan produksi dapat bekerja secara handal dan perusahaan dapat terhindar dari kerugian akibat production lost yang besar.

\section{KAJIAN PUSTAKA}

A. Maintenance

Menurut Supandi (1990) dalam Dholpina (2011), maintenance adalah kegiatan atau aktivitas untuk menjaga, memperbaiki atau mempertahankan kualitas peralatan dan mesin agar berjalan dengan baik seperti kondisi sebelumnya. Maintenance menurut Barry (2001) dalam Djunaidi (2012), maintenance diperlukan untuk mempertahankan kualitas dan meningkatkan produktivitas sehingga maintenance merupakan hal penting yang harus diperhatikan.

Berdasarkan pendapat dari definisi di atas dapat disimpulkan bahwa maintenance merupakan suatu kegiatan untuk merawat, memperbaiki suatu komponen mesin agar mesin atau peralatan dapat mempertahankan kualitas dan meningkatkan produktivitas secara aman, efektif, dan efisien sesuai yang telah direncanakan. Tujuan dari pelaksanaan kegiatan maintenance menurut Assauri (2008) dalam Dholpina (2011) sebagai berikut :

1. Mempertahankan kemampuan produksi sesuai dengan rencana produksi.

2. Menjaga kualitas produksi serta kegiatan produksi tidak terganggu.

3. Membantu mengurangi biaya yang diluar batas selama waktu yang tidak ditentukan sesuai dengan kebijakan perusahaan.

4. Menerapkan kegiatan maintenance yang efektif dan efisien sehingga dapat mencapai tingkat biaya maintenance yang serendah mungkin.

5. Menghindari kegiatan maintenance yang membahayakan karyawan.

6. Mencapai tujuan umum perusahaan dengan mengadakan kerja sama yang baik dalam fungsifungsi yang lain dalam perusahaan

Maintenance dalam suatu perusahaan sangat penting, hal tersebut karena permasalahan dalam maintenance menyangkut semua peralatan dalam perusahaan. Maintenance yang dilakukan oleh setiap perusahaan berbeda-beda. Menurut Dholpina (2011), maintenance dikelompokkan menjadi 2 yaitu preventive maintenance dan corrective maintenance :

\section{Preventive maintenance}

Maintenance preventive atau preventive maintenance merupakan kegiatan maintenance yang bertujuan mencegah terjadinya suatu kerusakan atau cara maintenance yang direncanakan untuk pencegahan seperti inspeksi, perbaikan kecil, pelumasan dan penyetelan. Maintenance tersebut dilakukan agar mesin atau peralatan yang beroperasi dapat terhindar dari kerusakan. Maintenance preventive sangat penting diterapkan pada perusahaan yang proses produksinya kontinyu. 
Keuntungan program preventif yang baik jika dilakukan perusahaan menurut Supandi (1990) dalam Dholpina (2011) adalah :

a. Downtime waktu berkurang.

b. Kerja lembur untuk tenaga maintenance berkurang.

c. Waktu menunggu peralatan yang dibutuhkan berkurang.

d. Pengeluaran biaya perbaikan berkurang.

e. Dapat menghemat penggantian suku cadang.

f. Kerusakan berkurang sehingga keselamatan kerja operator meningkat.

\section{Corrective maintenance}

Maintenance korektif atau corrective maintenance merupakan kegiatan maintenance yang dilakukan untuk memperbaiki dan meningkatkan kondisi peralatan atau mesin sehingga dapat kembali digunakan sesuai standar mesin. Maintenance korektif berupa tindakan penggantian atau perbaikan terhadap mesin yang mengalami kerusakan atau tidak dapat berfungsi dengan baik. Maintenance korektif bersifat menunggu sampai kerusakan terjadi baru dilakukan perbaikan.

\section{B. PENJELASAN UMUM ECR (Equipment Critically Rating)}

ECR (Equipment Critically Rating) merupakan sistem penilaian kekritisan equipment berdasar pada resiko terhadap produksi dan safety jika peralatan tersebut gagal.

Parameter ECR ada 2, yaitu parameter dampak dan parameter peluang (PT Petrokimia Gresik) :

\section{Parameter Dampak}

a. Insignificant

Sumber risiko (unsur atau komponen atau obyek dalam beraktivitas) tidak berdampak sama sekali, akibatnya tidak signifikan terhadap kelangsungan aktivitas sehingga aktivitas tetap terlaksana.

b. Minor

Sumber risiko (unsur atau komponen atau obyek dalam beraktivitas) berdampak kecil, akibatnya kecil terhadap kelangsungan aktivitas sehingga aktivitas masih terlaksana.

c. Moderate

Sumber risiko (unsur atau komponen atau obyek dalam beraktivitas) berdampak sedang, akibatnya sedang terhadap kelangsungan aktivitas sehingga aktivitas masih dapat terlaksana.

d. Major

Sumber risiko (unsur atau komponen atau obyek dalam beraktivitas) berdampak besar, akibatnya cukup signifikan terhadap kelangsungan aktivitas namun masih dapat terlaksana.

e. Catastrophic
Sumber risiko (unsur atau komponen atau obyek dalam beraktivitas) berdampak sangat besar terhadap finansial perusahaan, akibatnya sangat signifikan terhadap kelangsungan aktivitas sama sekali tidak dapat terlaksana.

\section{Parameter Peluang}

a. Rare

Apabila kondisi dan sumber risiko (unsur atau komponen atau obyek dalam beraktivitas) kemungkinan terjadinya sangat kecil (rare) atau sekitar $0-10 \%$

b. Unlikely

Apabila kondisi dan sumber risiko (unsur atau komponen atau obyek dalam beraktivitas) kemungkinan terjadinya sekali-kali (unlikely) atau sekitar $>10-30 \%$

c. Moderate

Apabila kondisi dan sumber risiko (unsur atau komponen atau obyek dalam beraktivitas) kemungkinan terjadinya sekali-kali (unlikely) atau sekitar $>30-50 \%$

d. Likely

Apabila kondisi dan sumber risiko (unsur atau komponen atau obyek dalam beraktivitas) kemungkinan terjadinya sering (likely) atau sekitar $>50-70 \%$

e. Certain

Apabila kondisi dan sumber risiko (unsur atau komponen atau obyek dalam beraktivitas) kemungkinan hampir selalu atau pasti terjadi (certain) atau sekitar $>70 \%$

Fungsi dari ECR (Equipment Critically Rating) adalah :

1. Untuk rujukan prioritas Work Order (WO).

2. Untuk prioritas pengadaan spare part inventory.

3. Untuk rujukan pemantauan kehandalan maintenance.

4. Equipment yang dilakukan RCM (Reliability Centered Maintenance) diprioritaskan equipment yang memiliki indeks kekritisan kategori A.

ECR secara umum dapat diklasifikasikan menjadi 4 kategori :

1. Kategori A : nilai 15-25, dan semua nilai Dampak $=5$.

2. Kategori B : nilai 4-12.

3. Kategori $\mathrm{C}$ : nilai 1-3.

4. Kategori L atau Lingkungan : equipment yang terkait regulasi pemerintah dan lingkungan.

Dari perhitungan yang didapat selanjutnya digolongkan dengan kategori mana equipment yang akan lebih diprioritaskan untuk prioritas WO (Work Order) dan pengadaan barang. Equipment dengan kategori L tingkat prioritasnya sama dengan kategori 
A karena resiko dampak terhadap manusia atau tenaga, peralatan, lingkungan, maupun reputasi perusahaan sangat besar.

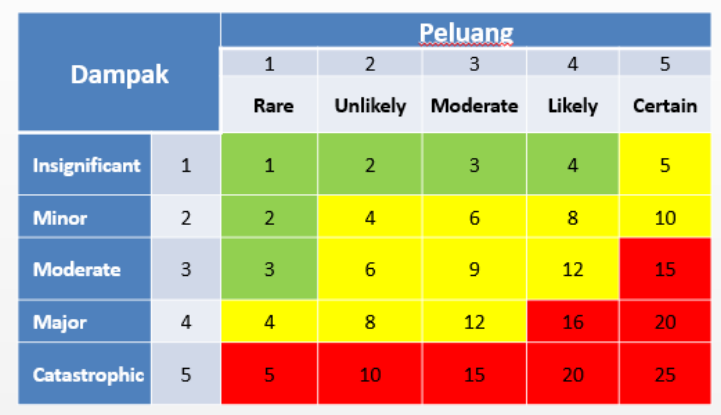

Gambar 2.1 Matrix ECR

(Sumber : PT Petrokimia Gresik)

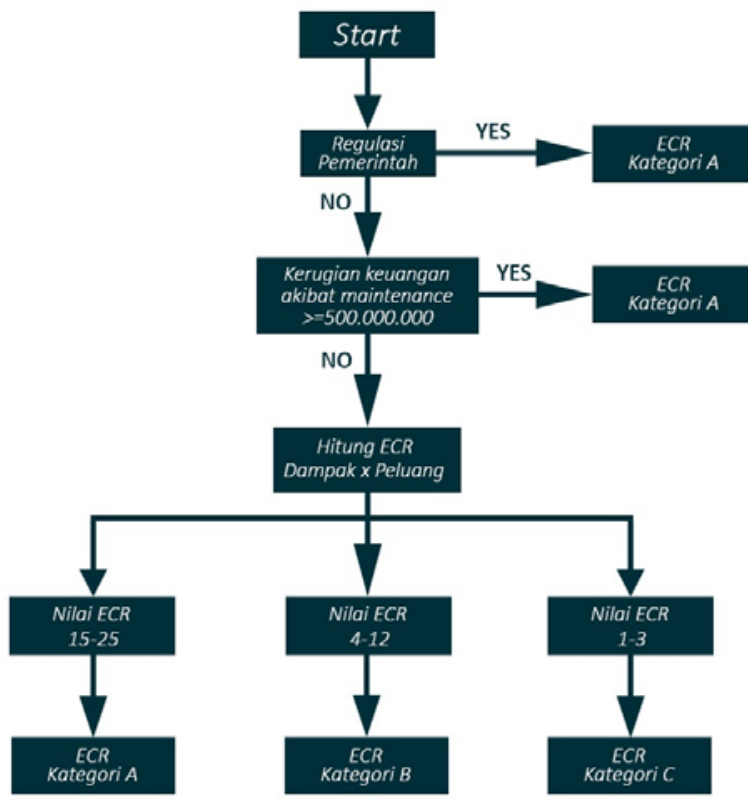

Gambar 2.2 Flow Chart ECR

\section{PENILAIAN KOMPONEN KRITIS (ECR)}

Penilaian komponen kritis atau yang biasa disebut dengan ECR (Equipment Critically Rating) adalah suatu metode yang digunakan untuk mengetahui nilai kekritisan dari equipment sehingga hasil penilaiannya dapat dijadikan input pada perencanaan sistem perawatan. Berdasarkan hasil ECR ini diharapkan dapat dilakukan perencanaan perawatan yang sistematis dan optimal berdasarkan skala prioritas dari ECR.

Nilai ECR didapat dari hasil analisa nilai dampak dikalikan dengan peluang terjadinya breakdown. Nilai dampak adalah nilai tertiggi dari 3 kategori penilaian (Safety Factor, Production Lost, dan Maintenance Cost), sedangkan nilai peluang didapat dari data historis maintenance equipment saat mengalami kegagalan fungsi atau breakdown. Penilaian ECR menggunakan pendekatan multi kriteria dengan kriteria sebagai berikut :

1. Keamanan (Safety Factor)

Penilaian keamanan dari suatu equipment didapat dari wawancara dengan operator produksi yang berkaitan dengan equipment secara langsung, sehingga data yang dihasilkan merupakan data yang valid. Nilai keamanan ini berkaitan dengan tingkat bahaya yang diakibatkan kepada operator produksi, lingkungan ataupun berdampak kepada reputasi perusahaan jika terjadi kegagalan fungsi equipment. Berikut tabel penilaian SHE :

Tabel 2.1 Kriteria Nilai SHE (Safety Healthy Environment)

\begin{tabular}{|l|l|}
\hline NILAI & SHE \\
\hline $\mathbf{1}$ & $\begin{array}{l}\text { Tidak menimbulkan kecelakaan kerja dan } \\
\text { lingkungan }\end{array}$ \\
\hline $\mathbf{2}$ & $\begin{array}{l}\text { Menimbulkan kecelakaan kerja ringan, korban } \\
\text { sadar, lingkungan }\end{array}$ \\
\hline $\mathbf{3}$ & $\begin{array}{l}\text { Menimbulkan kecelakaan kerja ringan, korban } \\
\text { tidak sadar }\end{array}$ \\
\hline $\mathbf{4}$ & Menimbulkan kecelakaan kerja berat \\
\hline $\mathbf{5}$ & Menimbulkan kecelakaan kerja korban jiwa \\
\hline
\end{tabular}

\section{Faktor Produksi (Production Lost)}

Ketika suatu equipment terjadi kegagalan fungsi sehingga harus dilakukan perbaikan, maka hal itu akan berdampak terhadap sistem proses produksi di dalam pabrik, hal ini dapat menyebabkan kerugian bagi perusahaan karena tidak dapat melakukan kegiatan produksi. Perhitungan nilai production lost diambil dari lamanya suatu equipment berhenti dalam setahun. Berikut tabel penilaian Production Lost :

Tabel 2.2 Kriteria Nilai Production Lost

\begin{tabular}{|l|l|}
\hline NILAI & PRODUCTION LOST \\
\hline $\mathbf{1}$ & Downtime $<1$ hari dalam setahun \\
\hline $\mathbf{2}$ & Downtime 1-2 hari dalam setahun \\
\hline $\mathbf{3}$ & Downtime $2,01-3$ hari dalam setahun \\
\hline $\mathbf{4}$ & Downtime $3,01-4$ hari dalam setahun \\
\hline $\mathbf{5}$ & Downtime $>$ 4 hari dalam setahun \\
\hline \multicolumn{2}{|}{} \\
$\quad$ (Sumber : PT Petrokimia Gresik)
\end{tabular}

\section{Maintenance Cost}

Perbaikan suatu equipment di perusahaan dapat mengeluarkan biaya yang besar dan merugikan perusahaan, karenanya, perusahaan akan berusaha secara optimal guna menurunkan pengeluaran akibat maintenance. Berikut tabel penilaian ECR untuk maintenance cost : 
Tabel 2.3 Kriteria Nilai Maintenance Cost

\begin{tabular}{|c|l|}
\hline NILAI & \multicolumn{1}{|c|}{ MAINTENANCE COST } \\
\hline $\mathbf{1}$ & $<=\operatorname{Rp~} 50.000 .000$ \\
\hline $\mathbf{2}$ & $<=\operatorname{Rp~} 100.000 .000$ \\
\hline $\mathbf{3}$ & $<=\operatorname{Rp~} 200.000 .000$ \\
\hline $\mathbf{4}$ & $<\operatorname{Rp} 500.000 .000$ \\
\hline $\mathbf{5}$ & $>=\operatorname{Rp~} 500.000 .000$ \\
\hline
\end{tabular}

(Sumber : PT Petrokimia Gresik)

\section{Peluang (Frekuensi kegagalan)}

Frekuensi kegagalan diperoleh dari data catatan historis maintenance equipment selama 7 tahun terakhir. Berikut kategori nilai Peluang :

Tabel 2.4 Kriteria Nilai Peluang

\begin{tabular}{|c|l|}
\hline NILAI & \multicolumn{1}{|c|}{ PELUANG } \\
\hline $\mathbf{1}$ & 10 tahun sekali \\
\hline $\mathbf{2}$ & 1 tahun sekali \\
\hline $\mathbf{3}$ & 3 bulan sekali \\
\hline $\mathbf{4}$ & 1 bulan sekali \\
\hline $\mathbf{5}$ & 1 minggu sekali \\
\hline
\end{tabular}

(Sumber : PT Petrokimia Gresik)

\section{MTBF (Mean Time Between Failure)}

Mean Time Between Failures (MTBF) adalah waktu yang diperkirakan berlalu antara kegagalan yang melekat pada sistem mekanik atau elektronik, selama operasi sistem normal. MTBF dapat dihitung sebagai rata-rata aritmetik (rata-rata) waktu antara kegagalan sistem. Istilah ini digunakan untuk sistem yang dapat diperbaiki. Definisi MTBF tergantung pada definisi apa yang dianggap sebagai kegagalan. Untuk sistem yang kompleks dan dapat diperbaiki, kegagalan dianggap sebagai kondisi diluar desain yang menempatkan sistem tidak berfungsi dan menjadi kondisi perbaikan. Semakin tinggi MTBF, semakin lama sebuah sistem akan bekerja sebelum gagal (Wikipedia).

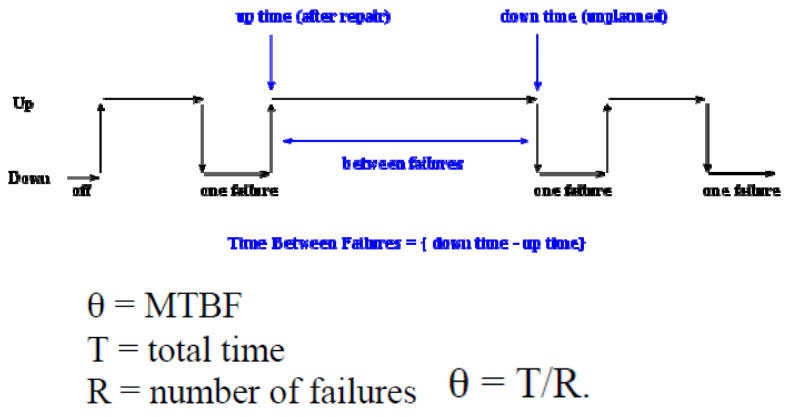

Gambar 2.3 Gambaran Rumus MTBF (Sumber : Vicor Reliability Engineering)
Secara umum, MTBF adalah "up-time" antara dua kondisi kegagalan dari sistem yang dapat diperbaiki selama operasi sebagaimana diuraikan di sini.

Mean Time Between Failure (MTBF) adalah rata rata waktu suatu mesin dapat dioperasikan sebelum terjadinya kerusakan. MTBF ini dirumuskan sebagai hasil bagi dari total waktu pengoperasian mesin dibagi dengan jumlah atau frekuensi kegagalan pengoperasian mesin karena breakdown. Satuan dari MTBF adalah hari, yang artinya adalah jumlah hari rata-rata equipment tersebut bekerja.

\section{HASIL DAN PEMBAHASAN}

\section{A. Proses Penggolongan ECR Berbasis Resiko}

ECR berbasis resiko merupakan kategori penggolongan berdasarkan pendekatan resiko (dampak dan peluang) yang dihadapi operator serta lingkungan saat equipment mengalami kegagalan fungsi. Equipment yang dianalisa penulis merupakan equipment yang berada di pabrik PA1 functional location B0102 PT Petrokimia Gresik. Perbaruan nilai ECR ini dilakukan selama 5 tahun sekali. Nilai ECR yang sudah di perbarui dapat digunakan untuk rujukan prioritas work order (WO), untuk rujukan prioritas pengadaan barang, serta untuk pemantauan kehandalan maintenance. Daftar equipment yang dianalisa pada functional locatin B0102 :

Tabel 3.3 Daftar Equipment Functional Location B0102

\begin{tabular}{|c|l|l|}
\hline No & \multicolumn{1}{|c|}{ Equipment } & \multicolumn{1}{|c|}{ Description } \\
\hline 1 & B-03D2302 & Feeding Rock Hopper \\
\hline 2 & B-03M2310 & Feeding Hopper \\
\hline 3 & B-03M2306A & Weigher A \\
\hline 4 & B-03M2306B & Weigher B \\
\hline 5 & B-03C2301 & Aeration Blower \\
\hline 6 & B-03M2305 & Ground Rock Bucket Elevator \\
\hline 7 & B-03R2301 & Premixer \\
\hline 8 & B-03M2301 & Agitator of Premixer \\
\hline No & Equipment & \\
\hline 9 & B-03R2302A & Digester A \\
\hline 10 & B-03M2302A & Agitator of Digester A \\
\hline 11 & B-03R2302B & Digester B \\
\hline 12 & B-03M2302B & Agitator of Digester B \\
\hline 13 & B-03R2302C & Digester C \\
\hline 14 & B-03M2302C & Agitator of Digester C \\
\hline 15 & B-03R2304 & Pump Tank \\
\hline 16 & B-03P2303 & No. 1 Vacuum Cooler Pump \\
\hline 17 & B-03D2311 & No.1 Vacuum Cooler \\
\hline
\end{tabular}




\begin{tabular}{|c|c|c|}
\hline 18 & B-03R2303 & Seal Tank \\
\hline 19 & B-03M2303 & Agitator of Seal Tank \\
\hline 20 & $\mathrm{~B}-03 \mathrm{P} 2301 \mathrm{~A}$ & Hemihydrate Slurry Pump A \\
\hline 21 & $\mathrm{~B}-03 \mathrm{P} 2301 \mathrm{~B}$ & Hemihydrate Slurry Pump B \\
\hline 22 & B-03FIL2321 & No. 1 Filter \\
\hline 23 & B-03D2325 & No.1 Filter Chute \\
\hline 24 & B-03C2322 & No. 1 Cloth Drying Fan \\
\hline 25 & $\mathrm{~B}-03 \mathrm{C} 2321$ & No. 1 Cake Blower \\
\hline 26 & B-03D2324 & Cleaning Water Separator \\
\hline 27 & B-03TK2335 & Cleaning Water Tank \\
\hline 28 & B-03M2335 & Agitator TK2335 \\
\hline 29 & $\mathrm{~B}-03 \mathrm{P} 2335 \mathrm{~A}$ & Cleaning Water Pump A \\
\hline 30 & $\mathrm{~B}-03 \mathrm{P} 2335 \mathrm{~B}$ & Cleaning Water Pump B \\
\hline 31 & $\mathrm{~B}-03 \mathrm{D} 2321 \mathrm{~A}$ & No.1 Filter Separator \\
\hline 32 & $\mathrm{~B}-03 \mathrm{D} 2321 \mathrm{~B}$ & No.1 Filter Separator \\
\hline 33 & B-03D2322 & No.1 Filter Mist Separator \\
\hline 34 & B-03D2323 & No.1 Filter Vacuum Washer \\
\hline 35 & B-03C2323 & No. 1 Vacuит Pump \\
\hline 36 & $\mathrm{~B}-03 \mathrm{P} 2331 \mathrm{~A}$ & First Filtrate Pump A \\
\hline 37 & $\mathrm{~B}-03 \mathrm{P} 2331 \mathrm{~B}$ & First Filtrate Pump B \\
\hline 38 & B-03TK2351 & Filter Acid Storage Tank \\
\hline 39 & B-03M2351 & Agitator of Filter Acid Storage Tank \\
\hline 40 & $\mathrm{~B}-03 \mathrm{P} 2351 \mathrm{~A}$ & Concentrator Feed Pump A \\
\hline 41 & B-03P2351B & Concentrator Feed Pump B \\
\hline 42 & $\mathrm{~B}-03 \mathrm{D} 2359$ & Sump Pit \\
\hline 43 & B-03M2359 & Agitator of Sump Pit \\
\hline 44 & B-03Р2359 & Sump Pump \\
\hline 45 & B-03TK2334 & Return Acid Tank \\
\hline 46 & B-03M2334 & Agitator of Return Acid Tank \\
\hline 47 & $\mathrm{~B}-03 \mathrm{P} 2334 \mathrm{~A}$ & Return Acid Pump B \\
\hline 48 & B-03P2334B & Return Acid Pump B \\
\hline 49 & B-03D2337 & Return Acid Density Measuring Box \\
\hline No & Equipment & $\begin{array}{r}\text { Description } \\
\end{array}$ \\
\hline 50 & $\mathrm{~B}-03 \mathrm{P} 2353$ & Sludge Recycle Pump \\
\hline 51 & B- $03 \mathrm{C} 2325$ & Air Compressor \\
\hline 52 & B-03D2301 & Ground Rock Hopper \\
\hline 53 & B-03M2307 & Air Slide \\
\hline 54 & $\mathrm{~B}-03 \mathrm{~V} 2308$ & Rotary Valve \\
\hline 55 & B-03M2309 & Rock Return Chain Conveyor \\
\hline 56 & B-03E2302 & Desuperheater \\
\hline 57 & B-03E2313 & No. 1 Condenser \\
\hline
\end{tabular}

\begin{tabular}{|c|c|c|}
\hline 58 & B-03E2314 & No. 2 Condenser \\
\hline 59 & B-03E2413 & No.3 Condenser \\
\hline 60 & B-03F2341 & Mist Separator \\
\hline 61 & B-03T2341 & No. 1 Fume Scrubber \\
\hline 62 & B-03J2311 & No.1 Ejector \\
\hline 63 & B-03J2312 & No.2 Ejector \\
\hline 64 & B-03M2304 & Agitator R2304 \\
\hline 65 & B-03M2371 & Agitator Sump Pit \\
\hline 66 & $\mathrm{~B}-03 \mathrm{P} 2302 \mathrm{~A}$ & Hemihydrate Recycle Pump \\
\hline 67 & B-03Р2302B & Hemihydrate Recycle Pump \\
\hline 68 & $\mathrm{~B}-03 \mathrm{P} 2331 \mathrm{C}$ & First Filtrate Pump \\
\hline 69 & B-03P2346A & Silicate Pump \\
\hline 70 & B-03Р2346B & Silicate Pump \\
\hline 71 & B-03Р2349 & Vacuum Washer Pump \\
\hline 72 & B-03P2350 & No. 2 H2sif6 Pump \\
\hline 73 & B-03Р2371 & Sump Pump \\
\hline 74 & B-03P2382A & Floculant Pump \\
\hline 75 & B-03Р2382B & Floculant Pump \\
\hline 76 & B-03TK2304 & Defoaming Agent Tank \\
\hline 77 & B-03Р2304 & Defoaming Agent Pump \\
\hline 78 & B-03P2305 & Defoaming Agent Pump \\
\hline 79 & B-03TK2349 & Vacuum Washer Tank \\
\hline 80 & $\begin{array}{l}\text { B- } \\
\text { 03TK2382A }\end{array}$ & Floculant Tank \\
\hline 81 & B-03M2382A & Agitator TK2382 A \\
\hline 82 & $\begin{array}{l}\text { B- } \\
\text { 03TK2382B }\end{array}$ & Floculant Tank \\
\hline 83 & B-03M2382B & Agitator TK2382 B \\
\hline
\end{tabular}

(Sumber : PT Petrokimia Gresik)

Tahap-tahap dalam menentukan nilai ECR sebagai berikut :

a. Proses Analisa Nilai Dampak

Nilai dampak disini merupakan nilai tertinggi dari 3 kategori (SHE, Production Lost, Maintenance Cost). Jika salah satu dari 3 kategori tersebut bernilai 5, maka nilai dampak dari equipment tersebut adalah 5. dan jika kegagalan equipment berdampak cukup besar terhadap lingkungan atau dapat merusak reputasi perusahaan maka nilai dampaknya adalah 5 .

1) Nilai SHE (Safety Healthy Environment)

Untuk mendapatkan nilai SHE, dilakukan wawancara terhadap pihak operator produksi yang berkaitan secara langsung dengan equipment yang dianalisa. Pihak terkait akan diwawancarai mengenai kemungkinan resiko serta dampak terhadap operator dan lingkungan jika equipment mengalami kegagalan 
fungsi. Kategori nilai SHE dapat dilihat pada Tabel 3.4

Tabel 3.4 Kriteria Nilai SHE (Safety Healthy Environment)

\begin{tabular}{|c|c|}
\hline NILAI & \multicolumn{1}{|c|}{ SHE } \\
\hline $\mathbf{1}$ & $\begin{array}{l}\text { Tidak menimbulkan kecelakaan kerja dan } \\
\text { ngkungan }\end{array}$ \\
\hline $\mathbf{2}$ & $\begin{array}{l}\text { Menimbulkan kecelakaan kerja ringan, korban } \\
\text { adar, lingkungan }\end{array}$ \\
\hline $\mathbf{3}$ & $\begin{array}{l}\text { Menimbulkan kecelakaan kerja ringan, korban } \\
\text { dak sadar }\end{array}$ \\
\hline $\mathbf{4}$ & Menimbulkan kecelakaan kerja berat \\
\hline $\mathbf{5}$ & Menimbulkan kecelakaan kerja korban jiwa \\
& (Sumber : PT Petrokimia Gresik)
\end{tabular}

2) Nilai Production Lost (PL)

Nilai production lost didapat dari data historis maintenance equipment selama 7 tahun terakhir, nilai PL merupakan rata-rata waktu mati atau equipment ketika dalam kondisi perbaikan atau mati sehingga tidak dapat melakukan proses produksi. Kategori nilai PL dapat dilihat pada Tabel 3.5

Tabel 3.5 Kriteria Nilai Production Lost

\begin{tabular}{|c|l|}
\hline NILAI & \multicolumn{1}{|c|}{ PRODUCTION LOST } \\
\hline $\mathbf{1}$ & Downtime $<1$ hari dalam setahun \\
\hline $\mathbf{2}$ & Downtime 1-2 hari dalam setahun \\
\hline $\mathbf{3}$ & Downtime 2,01-3 hari dalam setahun \\
\hline $\mathbf{4}$ & Downtime 3,01-4 hari dalam setahun \\
\hline $\mathbf{5}$ & Downtime $>4$ hari dalam setahun \\
\hline
\end{tabular}

(Sumber : PT Petrokimia Gresik)

3) Nilai Maintenance Cost (MC)

Nilai ini merupakan biaya yang dikeluarkan oleh perusahaan untuk perbaikan equipment terkait. Data historis maintenance cost ( 7 tahun) didapat dari karyawan bagian TA \& Reliabilitas yang ada di Departemen Pemeliharaan III, PT Petrokimia Gresik. Kategori nilai MC dapat dilihat pada Tabel 3.6

Tabel 3.6 Kriteria Nilai Maintenance Cost

\begin{tabular}{|c|c|}
\hline NILAI & MAINTENANCE COST \\
\hline $\mathbf{1}$ & $<=\operatorname{Rp~} 50.000 .000$ \\
\hline $\mathbf{2}$ & $<=\operatorname{Rp~} 100.000 .000$ \\
\hline $\mathbf{3}$ & $<=\operatorname{Rp} 200.000 .000$ \\
\hline $\mathbf{4}$ & $<\operatorname{Rp~} 500.000 .000$ \\
\hline
\end{tabular}

\begin{tabular}{|l|l|}
\hline 5 & $>=\operatorname{Rp~500.000.000~}$ \\
\hline
\end{tabular}

b. Proses Analisa Nilai Peluang (frekuensi kegagalan)

Dalam mencari nilai peluang penulis melakukan cek data historis (7 Tahun terakhir) maintenance dari equipment terkait, lalu mulai merumuskan asumsi untuk disesuaikan kedalam nilai yang terdapat pada tabel 3.7

Tabel 3.7 Kriteria Nilai Peluang

\begin{tabular}{|c|l|}
\hline NILAI & \multicolumn{1}{|c|}{ PELUANG } \\
\hline $\mathbf{1}$ & 10 tahun sekali \\
\hline $\mathbf{2}$ & 1 tahun sekali \\
\hline $\mathbf{3}$ & 3 bulan sekali \\
\hline $\mathbf{4}$ & 1 bulan sekali \\
\hline $\mathbf{5}$ & 1 minggu sekali \\
\hline & (Sumber : PT Petrokimia Gresik) \\
\hline
\end{tabular}

Setelah semua nilai tersebut sudah didapatkan maka selanjutnya dilakukan perhitungan nilai ECR dengan rumus :

\section{ECR : Dampak x Peluang}

(Sumber : PT Petrokimia Gresik)

Setelah mengetahui bobot kriteria yang dipakai dilanjutkan penilaian equipment dengan menggunakan ECR. Dapat dilihat pada gambar dibawah ini hasil perhitungan ECR : 


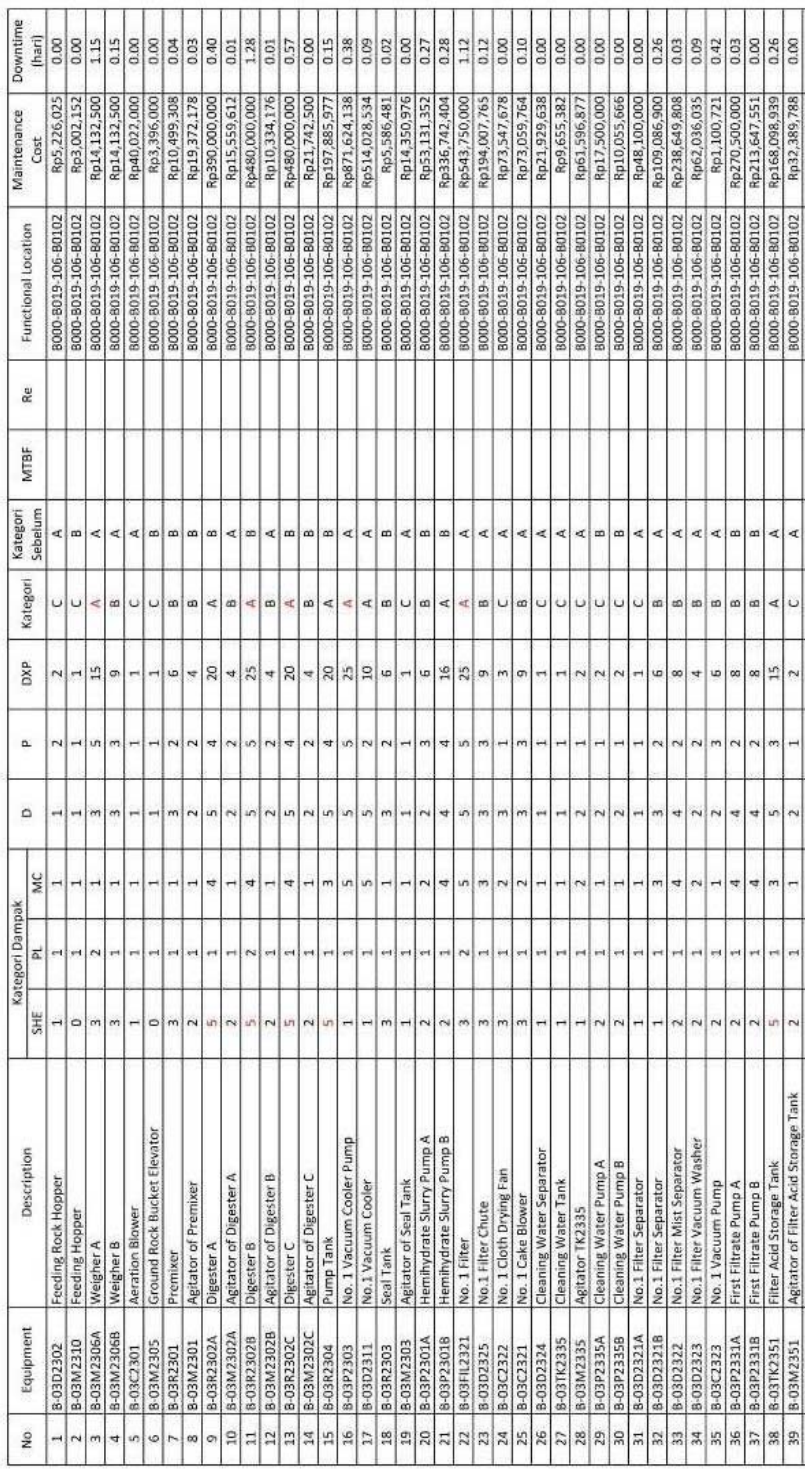

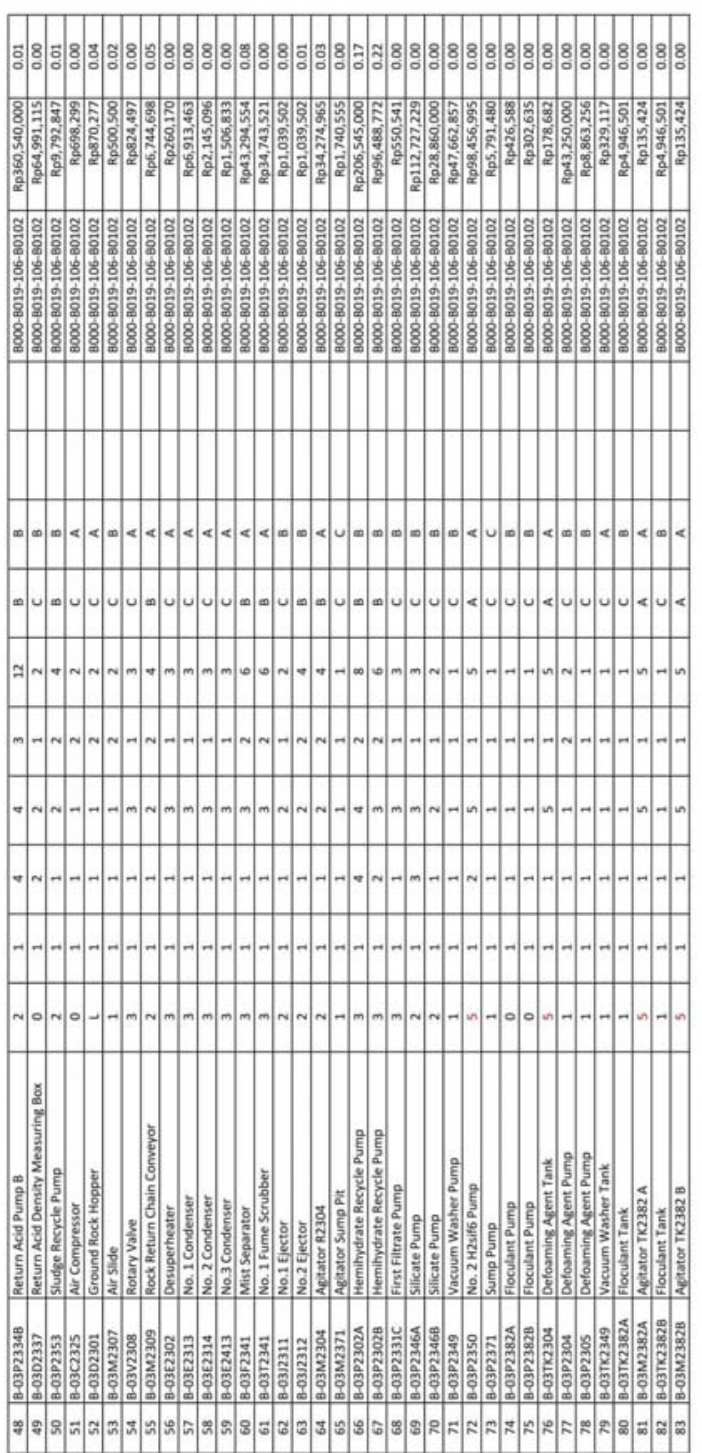

Gambar 3.7 Hasil Update ECR Dalam Bentuk Tabel

Dari hasil di atas terjadi beberapa penurunan kategori ECR (Equipment Critically Rating) dibandingkan dengan yang sebelumnya, hal ini dikarenakan perbedaan metode, ECR yang baru menggunakan metode resiko, sedangkan yang lama masih menggunakan kategori sebagai berikut: A (matikan pabrik), B (potong rate), C (tidak berpengaruh), L (lingkungan). Dari hasil update ECR ditemukan beberapa equipment yang sudah tidak digunakan (M2310, M2305, D2337, C2325, P2382A, P2382B) sehingga hal ini sangat berguna untuk menghemat biaya pengadaan barang dengan cara tidak membeli lagi kebutuhan equipment yang sudah digunakan tersebut. Terdapat beberapa equipment 
yang berdampak pada lingkungan dan dapat merusak reputasi perusahaan seperti equipment R2302A, R2302B, R2302C, R2304, TK2351, P2350, TK2304, M2382A, M2382B. equipment yang berdampak terhadap lingkungan masuk ke ECR kategori A.

\section{B. Analisa Kestabilan Maintenance dengan MTBF}

Dari data ECR (Equipment Critically Rating) yang telah diperbarui diatas, dilakukan tindak lanjut dengan pemantauan kestabilan maintenance dengan MTBF, hanya ECR kategori A serta yang berdampak terhadap lingkungan yang dilakukan pemantauan, hal ini dikarenakan equipment dengan kategori A dirasa sangat penting untuk dijaga kehandalannya. Rumus perhitungan nilai MTBF dengan hasil satuan (hari):

$$
\begin{aligned}
& \quad \theta=\mathrm{T} / \mathrm{R} . \\
& \theta=\mathrm{MTBF} \\
& \mathrm{T}=\text { total time } \\
& \mathrm{R}=\text { number of failures }
\end{aligned}
$$

\section{(Sumber : Vicor Reliability Engineering)}

Setelah dilakukan perhitungan nilai MTBF selama 7 tahun terakhir dari equipment dengan ECR kategori A, hasil grafiknya sebagai berikut :

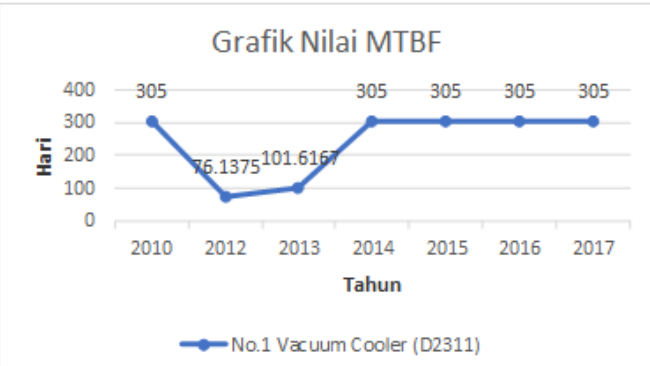

Gambar 3.8 Grafik Nilai MTBF Equipment D2311

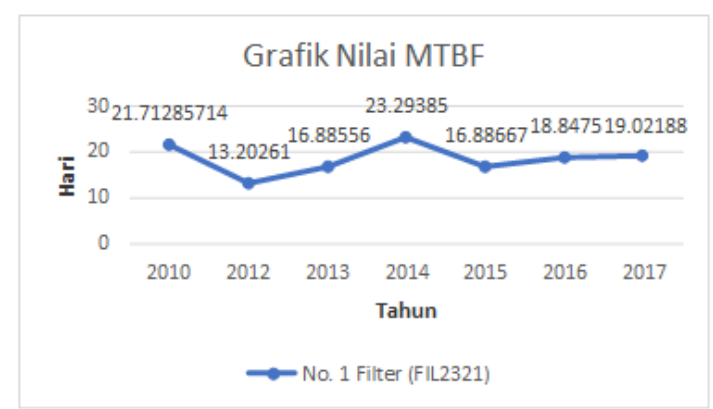

Gambar 3.9 Grafik Nilai MTBF Equipment FIL2321

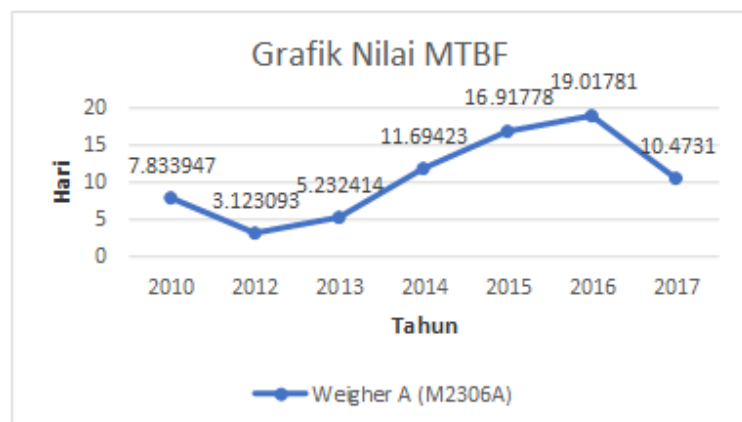

Gambar 3.10 Grafik Nilai MTBF Equipment M2306A

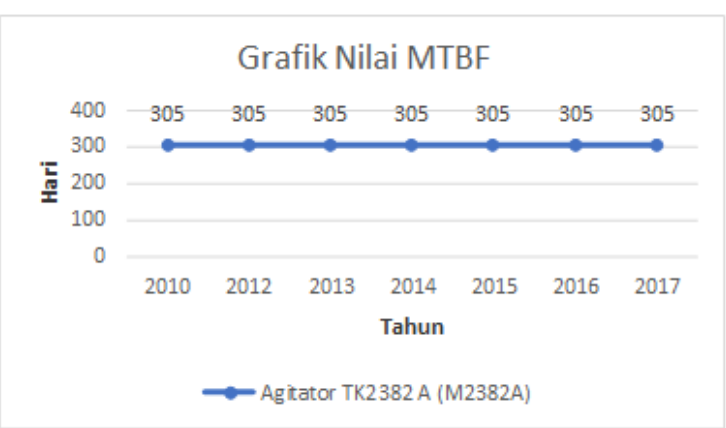

Gambar 3.11 Grafik Nilai MTBF Equipment M2382A

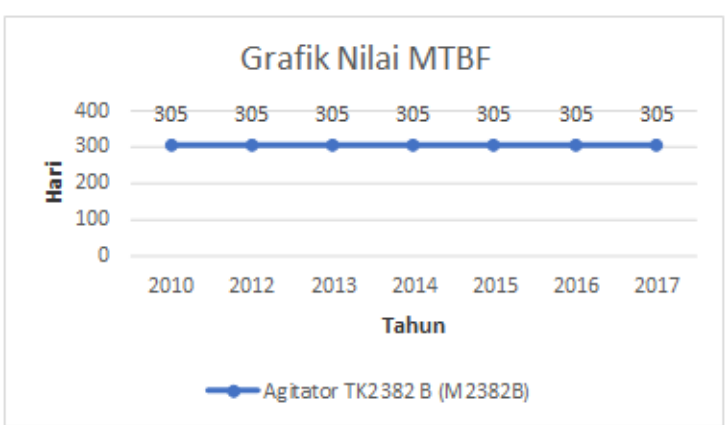

Gambar 3.12 Grafik Nilai MTBF Equipment M2382B

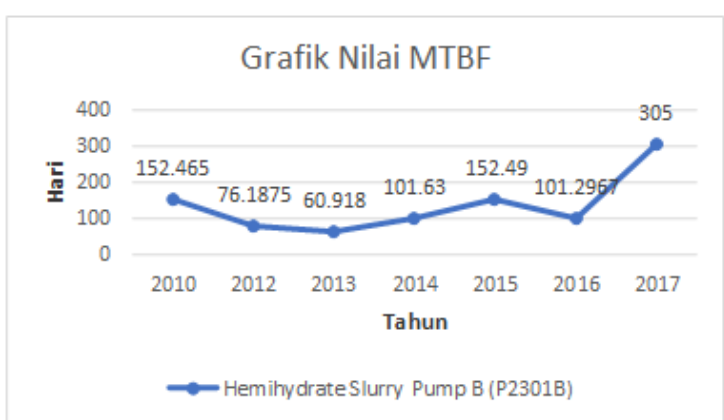

Gambar 3.13 Grafik Nilai MTBF Equipment P2301B 


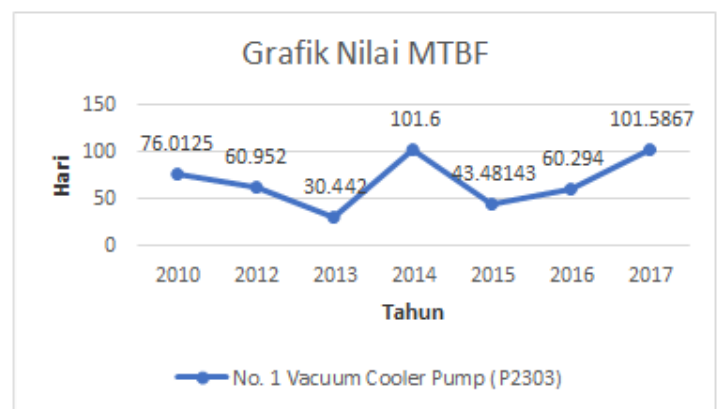

Gambar 3.14 Grafik Nilai MTBF Equipment P2303

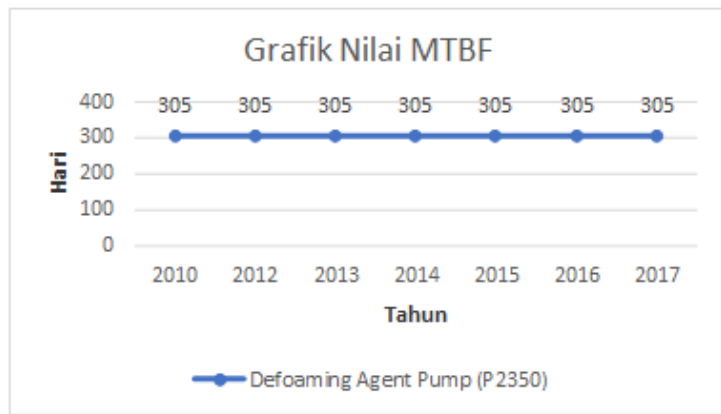

Gambar 3.15 Grafik Nilai MTBF Equipment P2350

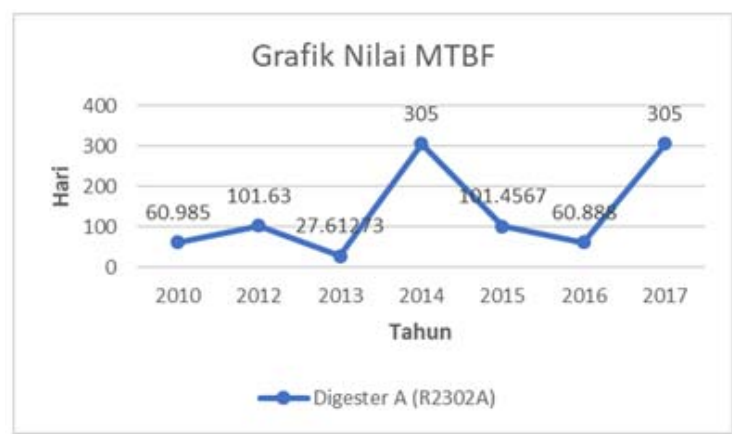

Gambar 3.16 Grafik Nilai MTBF Equipment P2302A

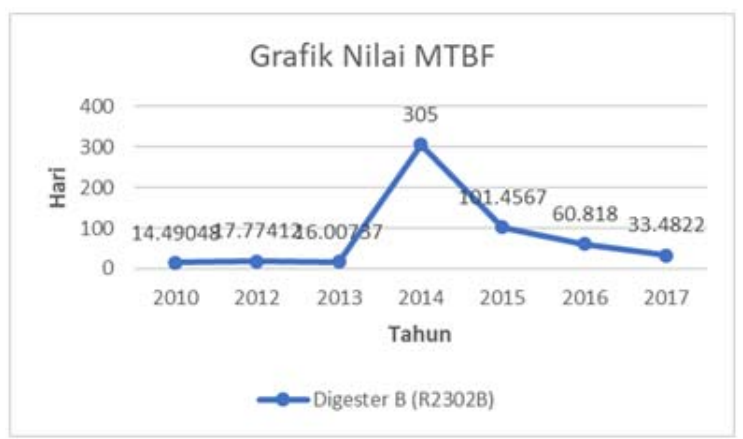

Gambar 3.17 Grafik Nilai MTBF Equipment P2302B

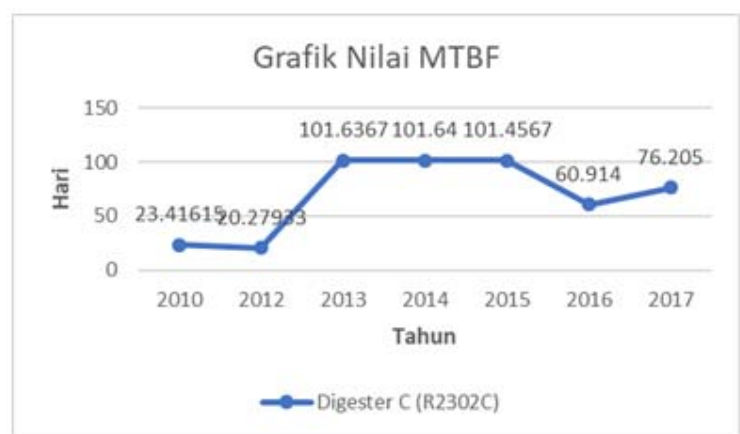

Gambar 3.18 Grafik Nilai MTBF Equipment R2302C

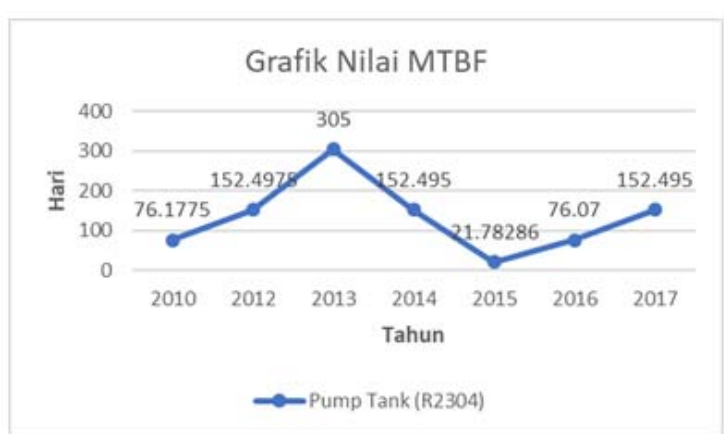

Gambar 3.19 Grafik Nilai MTBF Equipment R2304

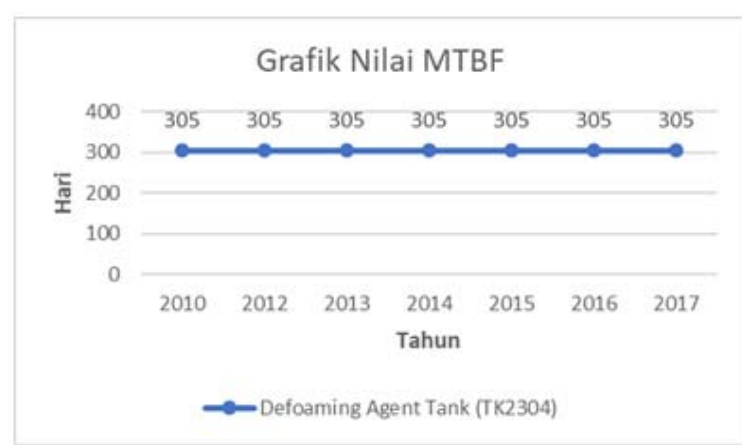

Gambar 3.20 Grafik Nilai MTBF Equipment TK2304

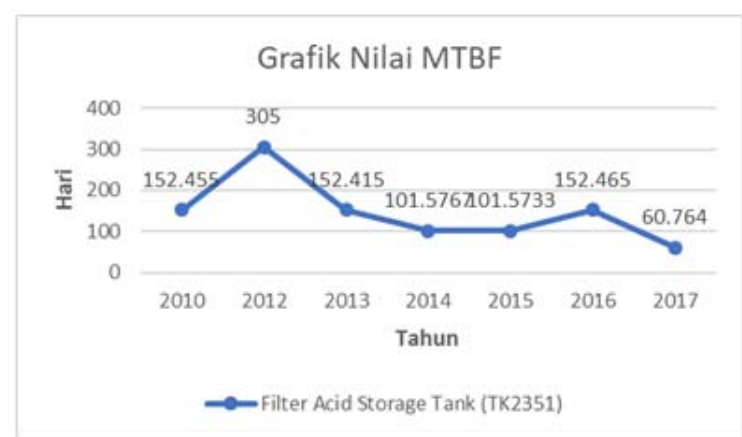

Gambar 3.21 Grafik Nilai MTBF Equipment TK2351

Dari hasil grafik diatas, ada beberapa equipment yang stabil di nilai 305 (merupakan rata-rata streamdays per 
tahun selama 7 tahun pengamatan), seperti equipment TK2304, P2350, M2382B, M2382A, hal itu karena equipment tidak terjadi breakdown selama periode pengamatan. Selain trend MTBF equipment yang stabil tersebut, terdapat beberapa equipment dengan nilai MTBF yang cenderung turun tiap tahun seperti equipment TK2351, ini artinya penanganan maintenance kurang efektif karena rata-rata waktu mesin bekerja selalu menurun dari tahun ke tahun.

\section{PENUTUP}

\section{A. Simpulan}

Setelah melakukan Praktik Industri di PT Petrokimia Gresik, maka dapat diambil beberapa simpulan diantaranya sebagai berikut:

1. Hasil update ECR (Equipment Critically Rating) pada pabrik PA1 functional location B0102 ditemukan beberapa equipment yang sudah tidak digunakan, beberapa equipment turun tingkat krtitisnya dibandingkan dengan sebelumnya, hal ini dikarenakan perbedaan metode dalam penggolongan ECR. Metode yang saya gunakan merupakan metode baru yang diterapkan tahun 2018 oleh Departemen Pemeliharaan III PT Petrokimia Gresik.

2. Data Trend MTBF dari equipment kategori A menunjukan banyaknya peralatan yang belum handal, kegiatan maintenance di Departemen Pemeliharaan III masih kurang efektif sehingga rata-rata waktu equipment bekerja dalam satu tahun tidak stabil.

\section{A. Saran}

Saran yang dapat saya berikan adalah sebagai berikut:

1. Kegiatan pendataan maintenance di PT Petrokimia Gresik seharusnya lebih lengkap dalam penyebutan nama equipment, karena masih ada beberapa data yang tidak ada keterangan maintenance equipment $\mathrm{A} / \mathrm{B} / \mathrm{C}$. hal ini perlu diperbaiki agar dapat menghasilkan data yang valid.

2. Perlu dilakukan maintenance dengan metode RCM (Reliability Centered Maintenance) yang terencana dengan baik agar kehandalan equipment dapat meningkat.

3. Perusahaan harus lebih memperhatikan K3LH (Keamanan, Kesehatan, Keselamatan Kerja Lingkungan Hidup) dan 5R (Ringkas, Rapih, Resik, Rawat, Rajin) terhadap para karyawannya agar dalam proses produksi berjalan dengan aman, baik, dan tepat waktu.

\section{REFERENSI}

[1] Abernethy, R.B. 2000. Reliability and MTBF Overview. Vicor Reliability Engineering.

[2] Adib, Mohammad. 2011. Etnografi Madura. Surabaya: Departemen Antropologi Fakultas Ilmu Sosial dan Ilmu Politik Universitas Airlangga

[3] Bagian K3. 2016. Prosedur Kesehatan dan Keselamatan Kerja PT Petrokimia Gresik. Gresik.

[4] Bagian Personalia. 2016. Profil Perusahaan PT Petrokimia Gresik, PT Petrokimia Gresik. Gresik.

[5] Bagian TA dan Reliabilitas. 2018. Prosedur Update Equipment Critically Rating, PT Petrokimia Gresik. Gresik.

[6] Dolphina, E. 2011. Laporan Praktik Industri PT Petrokimia Gresik. Madura: Jurusan Teknik Industri Fakultas Teknik Universitas Trunojoyo.

[7] Supandi. 1990. Manajemen Perawatan Industri. Bandung: Ganeca Exact.

[8] Suryadi, Kadarsah. 2009. Identifikasi Kekritisan Komponen Pada Lini Produksi Pabrik Gula Tebu Menggunakan Metode Equipment Critical Rating.

[9] https://en.wikipedia.org/wiki/Mean_time_between_failures (diakses pada 20 Agustus 2018). 